\title{
Brightness constancy under a gradient of illumination'
}

EImer H. Davidson and Robert H. Freeman, Jr. PENNSYLVANIA STATE UNIVERSITY

\begin{abstract}
Ten undergraduates, five with and five without fixation, matched the brightness of two self-luminous disks at different positions on a reflecting background illuminated by an approximately linear gradient of illuminance. Judgments approaching brightness constancy were obtained even when the luminance of the test fields exceeded that of the background. The effect of the background was slightly, but not significantly, greater with fixation than without.
\end{abstract}

\section{Problem}

A persistent problem of brightness vision is the approximate invariance of the brightness of reflecting surfaces with variations in intensity of illumination (brightness constancy). An early explanation of brightness constancy was in terms of brightness contrast or induction (Hering, 1964). More recently, brightness contrast in man has been attributed to intra-retinal inhibitory processes analogous to those observed in the compound eye of Li mulu s (Diamond, 1960; Hartline \& Ratliff, 1957). However, recent research on brightness induction (Diamond, 1953; Leibowitz, Mote, \& Thurlow, 1953; Heinemann, 1955) has shown that brightness induction is minimal or absent under conditions in which inducing-field luminances fall below test-field luminances. Similarly, Leibowitz, Myers, \& Chinetti (1955) have shown that the induction effect in brightness constancy is also negligible under conditions in which surround-field reflectances are equal to or less than test-field reflectance. These authors therefore attribute the brightness constancy phenomenon in part to the same retinal mechanisms which are assumed to underlie simultaneous brightness induction. However, most brightness induction and brightness constancy experiments have been conducted under conditions of discrete illumination differences between the test and comparison fields, whereas object brightness comparisons under conditions of brightness gradients are far more typical of photometric conditions pertaining, for example, to indoor walls under illumination from quasi-point sources such as small windows and incandescent and even fluorescent lamps. The purpose of this experiment, therefore, was to determine the nature of brightness matches between two fields positioned at different locations on a background of continuously varying brightness, when the luminance of the test field exceeded that of the surrounding background.

\section{Method}

The "background" was a $4 \times 6 \mathrm{ft}$ sheet of commercial glass whose first surface was painted flat white. The glass was positioned normal to the observer's primary visual axis at a distance of 52 in. The test and comparison stimuli were generated by scraping away the white paint in two circular areas, of 3-in diameter and 36 in apart, so as to permit the passage of light through the glass from behind the background field. The stimulus fields subtended a visual angle of $3^{\circ}$ at an angular separation of approximately $38^{\circ}$. In line with $S^{\prime}$ 's eye and each of the two circular apertures were two test surfaces, consisting of two $16 \times 16$ in pieces of flat glass whose first surfaces were painted with the same batch of flat white paint. The distance of each of the two test surfaces from a partially shielded 12-in fluorescent source mounted behind the background field, and hence their illumination, was variable.

The S's side of the background field was illuminated indirectly by two 6-ft G。E. F72T12-CW cool white fluorescent bulbs wound with a grounding wire to assure rapid starting (Behar, 1960). The light was reflected from a white surface through a wedge-shaped aperture, whose width varied continuously for the entire length of the light source, onto the background field and thence into the observer's eye. Lateral scattering of light was limited by a large number of flat black vanes placed at 1-in intervals. The result was that the illumination varied in a continuous and approximately linear gradient from the left to the right end of the background field.

On each trial, the background and test fields were observed monocularly for a period of $6 \mathrm{sec}$., following which the illumination of the test fields was extinguished and the ceiling lights turned on. The staircase psychophysical method was used (Cornsweet, 1962). All observers made brightness matches with the standard test field on the left and on the right, and for all levels of luminance of the standard, with test field luminances both greater and approximately equal to the surrounding luminance of the background. The luminance immediately above and below the test-field aperture on the right was $-.496 \log \mathrm{ft}-\mathrm{L}$. , and on the left, $-.889 \mathrm{log}$ $\mathrm{ft}-\mathrm{L}$., as measured with a Macbeth illuminometer. The dependent measure was the luminance of the comparison field required to obtain a visual brightness match with the standard.

Five Ss made all of their judgments without restriction of eye movements (Non-Fixation Group) and, according to their reports, typically looked back and forth at the standard and comparison test fields while judging. These Ss made their judgments in two different sessions both with and without a vertical black dividing contour 1 in wide positioned equidistant between the two 


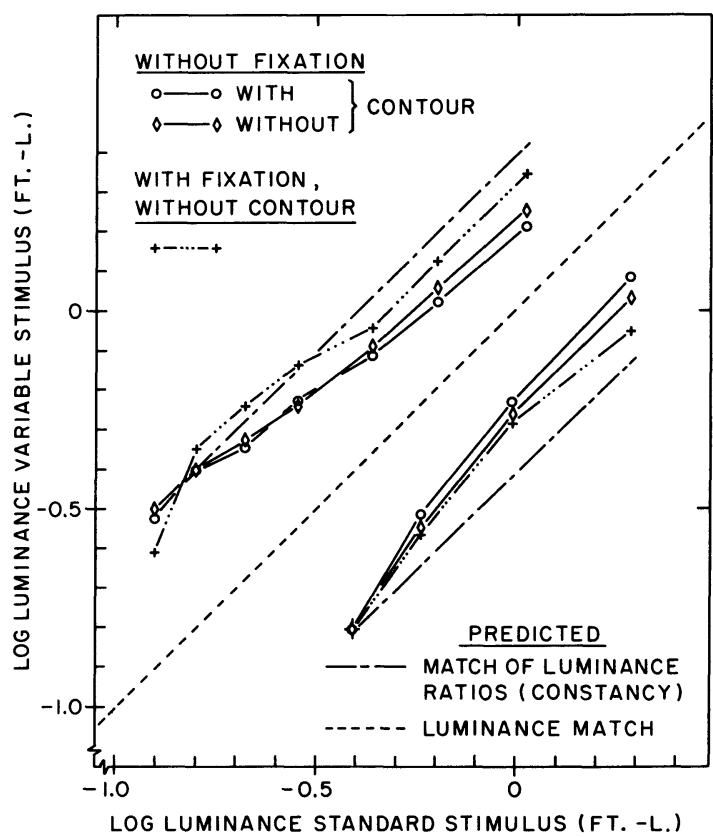

Fig. 1. Comparison-field luminances yielding a brightness match as a function of test-field luminance.

test fields. Another five Ss (Fixation Group) made their judgments without the center contour, but while fixating a small black dot halfway between the two test fields. Ss in the Fixation Group were not tested with the contour.

\section{Results}

The results of both groups are plotted in Fig. 1 on a $\log -\log$ plot. The log luminance deviation from a straight luminance match is represented by the vertical distance from the dotted line labeled "Luminance Match." A match of the luminance ratio of standard and variable test fields to their respective surrounds is indicated by the dashed line, which, in all cases, is $.4 \log \mathrm{ft}-\mathrm{L}$. above or below a luminance match. The results in all three conditions indicate brightness matches approaching "constancy." In almost all cases, the Fixation Group showed somewhat greater constancy than the Non-Fixation Group, although the effect of fixation was not significant for either position of the test field $(F(1,8)=0.80$ and 1.23$)$. For the Non-Fixation Group, "constancy" was somewhat greater without the contour than with. Again, the effect was not significant (F $(1,31)=3.73$ and 2.31 ). For all groups, an almost perfect luminance-ratio match was obtained when the standard test and background luminances were nearly equal. As the luminance of the former increased above that of the latter, "constancy" declined somewhat.

\section{Diseussion}

The results of this study indicate that brightness judgments approaching those predicted by the constancy law are obtainable under experimental conditions even when the luminance of the test stimulus is as much as seven times as great as that of the surrounding field. On the other hand, the approximation to constancy was not uniform throughout the range of test-stimulus luminance, indicating that the magnitude of the effect of the surrounding field is not independent of testfield luminance. In this respect, the results are consistent with the recent findings of Jameson \& Hurvich (1961) that the nature of the effect of a surround on a luminous test field depends upon their luminous difference. The results do not support the brightness induction hypothesis. Neither eye-movements nor $\mathrm{a}^{\text {' }}$ "phenomenal" separation of the test and comparison fields by a discriminable contour affected the generality of the results significantly.

\section{Relerences}

BEHAR, I. A new tachistoscope for animals and man. Amer. J. Psychol., 1960, 73, 305-306.

CORNSWEET, T. N. The staircase-method in psychophysics. Amer. J. Psychol., 1962, 75, 485-491.

DIAMOND, A. L. Foveal simultaneous brightness contrast as a function of inducing- and test-field luminances. J. exp. Psychol., 1953, 45, 304-314.

DIAMOND, A. L. A theory of depression and enhancement in the brightness response. Psychol. Rev., 1960, 67, 168-199.

HARTLINE, H. K., \& RATLIFF, F. Inhibitory interaction of receptor units in the eye of Limulus. J. gen. Physiol., 1957, 40, 357-376.

HEINEMANN, E. G. Simultaneous brightness induction as a function of inducing- and test-field luminances. J. exp. Psychol., 1955, 50, 89-96.

HERING, E. Outlines of a theory of the light sense (Trans. L. M. Hurvich \& Dorothea Jameson). Cambridge: Harvard University Press, 1964. Pp. 13-21.

JAMESON, DOROTHEA, \& HURVICH, L. M. Complexities of perceived brightness. Science, 1961, 133, 174-179.

LEIBOWITZ, H., MOTE, F. A., \& THURLOW, W. R. Simultaneous contrast as a function of separation between test and inducing fields. J. exp. Psychol., 1953, 46, 453 456.

LEIBOWITZ, H., MYERS, NANCY A., \& CHINETTI, P. The role of simultaneous contrast in brightness constancy. J. exp. Psychol., $1955,50,15-18$.

\section{Note}

1. Supported by NIMH Grant 08856 to the second author. 